\title{
Astrocytes Cultured from Mature Brain Derive from Glial Precursor Cells
}

\author{
William T. Norton and Muhammad Farooq \\ Departments of Neurology and Neuroscience, Albert Einstein College of Medicine, Bronx, New York 10461
}

We have previously shown that enriched preparations of oligodendrocytes from either mature bovine brain or 30-dold rat brain, when cultured in serum-free medium, yield mixed cultures of oligodendrocytes and astrocytes even though no GFAP + cells were present after $24 \mathrm{hr}$ in culture (Norton et al., 1986, 1988). To test the possibility that the astrocytes in these cultures arose from glial precursor cells, we followed the expression of ganglioside $\mathrm{GD}_{3}$, galactosylceramide (GC), glial fibrillary acidic protein (GFAP), and vimentin in the cultures. $\mathrm{GD}_{3}$ has already been shown to be a marker of immature neuroectodermal cells, which in the postnatal brain are glial progenitor cells (Goldman et al., $1984,1986)$. The cultures from both species contained at 1 DIV only two populations of cells; $90-95 \% \mathrm{GC}+/ \mathrm{GD}_{3}-$ oligodendrocytes and $4-10 \% \mathrm{GD}_{3}+/ \mathrm{GC}-$ small, round cells. With time, the oligodendrocytes remained $\mathrm{GD}_{3}-/ \mathrm{GFAP}-/$ vimentin-. The kinetics of antigen expression of the $\mathrm{GD}_{3}+$ cells could best be interpreted by the following sequence:

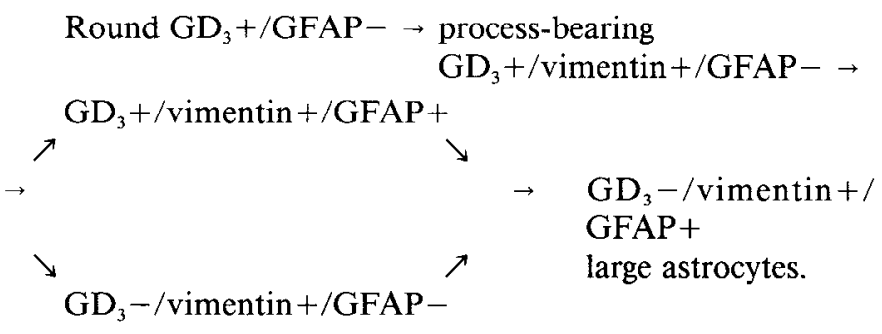

We interpret these results to show that the astrocytes arose from a small population of $\mathrm{GD}_{3}+$ glial precursor cells present in the brain that were co-isolated with oligodendroglia. No evidence was obtained that these $\mathrm{GD}_{3}+$ cells could also differentiate into oligodendrocytes.

We have shown that oligodendrocytes, isolated from adult bovine brain or 30-d-old rat brain and grown in serum-containing medium, yield mixed cultures containing oligodendrocytes, astrocytes, and some fibroblasts (Norton et al., 1986, 1988). When

\footnotetext{
Received Mar. 25, 1988; revised July 18, 1988; accepted July 18, 1988.

This work was supported by USPHS Grants NS-02476 and NS-23705 and by National Multiple Sclerosis Society Grant 1089. We are grateful to Dr. James Goldman for many fruitful discussions and to Ms. Renee Sasso for secretarial assistance.

Correspondence should be addressed to Dr. William T. Norton, Department of Neurology, Albert Einstein College of Medicine, 1300 Morris Park Avenue, Bronx, NY 10461

Copyright (C) 1989 Society for Neuroscience $0270-6474 / 89 / 030769-07 \$ 02.00 / 0$
}

such cultures were transferred to the 01 serum-free medium of Bottenstein (1986) at 3-5 din vitro (DIV), only oligodendrocytes and glial fibrillary acid protein-positive (GFAP+) astrocytes were obtained. These cultures did not contain any GFAP + cells initially, and the astrocytes appeared to arise from a proliferating population of vimentin $+/$ GFAP - flat cells. Purified astrocyte cultures could be obtained from mixed bovine cell cultures in 01 medium by shaking off the oligodendrocytes, and cytoskeletal preparations from the adherent cells contained much more vimentin than GFAP.

The properties of the astrocyte cultures from adult bovinc brain are similar to those described for cultures of neonatal rat brain. The latter cultures arise from glial precursor cells present in the germinal subventricular zone (Juurlink et al., 1981; Goldman et al., 1986). These precursor cells presumably represent a small percentage of the total number of cells initially dissociated from rat forebrain and are GFAP-. They proliferate rapidly and within a week form confluent cultures, most cells of which express both vimentin and GFAP. Intermediate filaments of these primary astrocytes also contain much more vimentin than GFAP (Chiu et al., 1981; Chiu and Goldman, 1984), a pattern associated with immature astrocytes (e.g., Bovolenta et al., 1984). It seemed reasonable to propose, therefore, that astrocytes in cultures of mature oligodendrocytes also arose from glial precursor cells rather than from fully differentiated astrocytes that might have been present in the original cell isolates.

The present study was designed to explore that postulate using, as a marker for precursor cells, reactivity to a monoclonal antibody to the disialoganglioside $\mathrm{GD}_{3}$ (ceramide-glc-gal-NANANANA). Goldman and his colleagues have shown that antibody R24, which was raised to a human melanoma cell line and shown to react specifically with $\mathrm{GD}_{3}$ (Pukel et al., 1982), binds to both neuronal and glial precursor cells in the germinal zones of young rats (Goldman et al., 1984). In vitro studies of neonatal rat brain cultures by the same group show that most of the astrocytes that develop in these cultures derive from $\mathrm{GD}_{3}+/$ GFAP - cells. As they differentiate, they lose the ability to bind the $\mathrm{GD}_{3}$ antibody (Goldman et al., 1986). The small, round cells that grow on top of the astrocyte monolayer are also $\mathrm{GD}_{3}+$, and most of these eventually become $\mathrm{GC}+$. Thus, $\mathrm{GD}_{3}$ marks precursor cells that in vitro can give rise to both astrocytes and oligodendrocytes. In vivo, however, these $\mathrm{GD}_{3}+$ cells in the subventricular zone of late prenatal to early postnatal rats appear to develop only into oligodendrocytes (LeVine and Goldman, 1988).

Pilot studies showed that our oligodendroglial preparations from both adult bovine brain and 30-d-old rat brain contained detectable numbers of $\mathrm{GD}_{3}+/ \mathrm{GC}-$ cells. The behavior of these preparations in culture was then charted by quantitative immunocytochemical analyses. 


\section{Materials and Methods}

Cell culture. Oligodendrocytes were isolated from fresh calf white matter and from the forebrains of 30-d-old rats by the methods of Farooq et al. (1981) and Snyder et al. (1980), respectively. The calves were about 4 months old and weighed approximately $160-180 \mathrm{~kg}$ (a full-grown steer weighs about $450 \mathrm{~kg}$ ). The cell fractions were taken up in tissue culture medium and plated in $60 \mathrm{~mm}$ plastic dishes coated with poly-L-lysine at a density of approximately $4 \times 10^{5}$ cells $/ \mathrm{cm}^{2}$. The cultures were maintained at $37^{\circ} \mathrm{C}$ in $5 \% \mathrm{CO}$ and the medium was changed every 3 $4 \mathrm{~d}$. The medium consisted of MEM with Earle's salts, $1 \times$ penicillinstreptomycin-Fungizone mixture, $2 \mathrm{~mm}$ glutamine, either 15\% heatinactivated calf serum or $15 \%$ heat-inactivated fetal calf serum (all from GIBCO, Grand Island, NY), and $0.5 \%$ glucose.

Immunocytochemistry. The sources of antibodies and dilutions used were as follows: a rabbit antiserum to human GFAP (Goldman and Chiu, 1984), 1:50, monoclonal antibody to vimentin (BoehringerMannheim), 1:30, rabbit antiserum to galactosylceramide (GC) (Raine et al., 1981a), 1:50, and monoclonal antibody R24 (Pukel et al., 1982) (kindly donated by Dr. Kenneth Lloyd, Sloan-Kettering Cancer Institute, New York), 1:200. All staining was done by the indirect double-antibody technique. The secondary antibodies used were rhodamine-labeled goat anti-rabbit IgG (Miles Laboratories, Naperville, IL), fluorescein-labeled goat anti-rabbit IgG (Miles), rhodamine-labeled goat anti-mouse IgG (Cappel, Malvern, PA), and fluorescein-labeled goat anti-mouse IgG (Cappel), all used at dilutions of 1:250.

Immunofluorescent staining was performed on cells growing on plastic Petri dishes fixed $30 \mathrm{~min}$ in $3.7 \%$ paraformaldehyde. Rings were enscribed on the plastic to prevent diffusion of reagents and the plastic dishes were cut apart, after mounting, for microscopic observation. For detection of GFAP and vimentin, fixation was followed by $10 \mathrm{~min}$ treatment with cold methanol. The cells were washed in PBS and treated with the antiserum diluent for $15 \mathrm{~min}$. This was removed and the antibody applied in the same diluent for $30 \mathrm{~min}$. The diluent was a mixture of $10 \%$ normal lamb serum, $10 \%$ fetal calf serum, $40 \%$ PBS, and $40 \%$ HEPES-buffered MEM. The first antibody was removed, and the cells washed in Puck's saline G, and the appropriate second, fluorescent antibody applied for $30 \mathrm{~min}$. Each culture was routinely doublestained for $\mathrm{GC} / \mathrm{GD}_{3}$ and for $\mathrm{GFAP} / \mathrm{GD}_{3}$. Binding of vimentin antibody was performed less regularly. When double staining for GFAP/GD and vimentin/ $\mathrm{GD}_{3}$, the staining protocol with the R24 antibody was performed first. The cells were finally washed in Puck's saline $G$ and mounted in Gelvatol. Preparations were examined with a Zeiss fluorescent microscope having the appropriate filters for rhodamine and fluorescein fluorescence.

Quantitation. Each slide was counted by 2 investigators using both a $40 \times$ objective and a $63 \times$ oil-immersion objective, and the results averaged. For the bovine cultures, at least 5 random fields, and for the rat cultures at least 10 random fields were counted on each slide. Counts included total cells, round cells, and flat process-bearing cells using phase optics, and antigen-positive cells (and their morphologies) and doublestained cells using appropriate filters for fluorescein and rhodamine fluorescence. Bovine cultures averaged $800-1100$ cells $/ 5$ fields at $400 \times$ throughout the 1-6 d period studied. Rat cultures were more variable. At the same magnification there were approximately 300 cells $/ 10$ fields at 1 DIV, 160-200 cells/10 fields at 5 DIV, and 400-500 cells/10 fields at $11 \mathrm{DIV}$. The maximum interinvestigator difference in counts for $\mathrm{GC}+$ cells was $12 \%$; but differences between cell counts of smaller categories such as $\mathrm{GD}_{3}+$ cells, or GFAP+ cells, were as high as $30 \%$.

\section{Results}

Bovine cells

\section{In $M E M$-calf serum}

The results of a typical experiment are plotted in Figure 1. The $\mathrm{GC}+$ oligodendrocytes have not been plotted in order to amplify the categories that contain only small numbers of cells. The $\mathrm{GC}+$ cells (which were $\mathrm{GD}_{3}-$ ) were, at days $1,2,3,4$, and 6 , respectively, $97.0,96.1,93.8,96.2$, and $89.4 \%$ of the total. Initially, these were small, round process-free cells, which, by 6 DIV, had begun to extend short processes.

The remaining cells fell into 2 major categories. The first category consisted of round $\mathrm{GD}_{3}+/ \mathrm{GC}-$ cells, somewhat small-

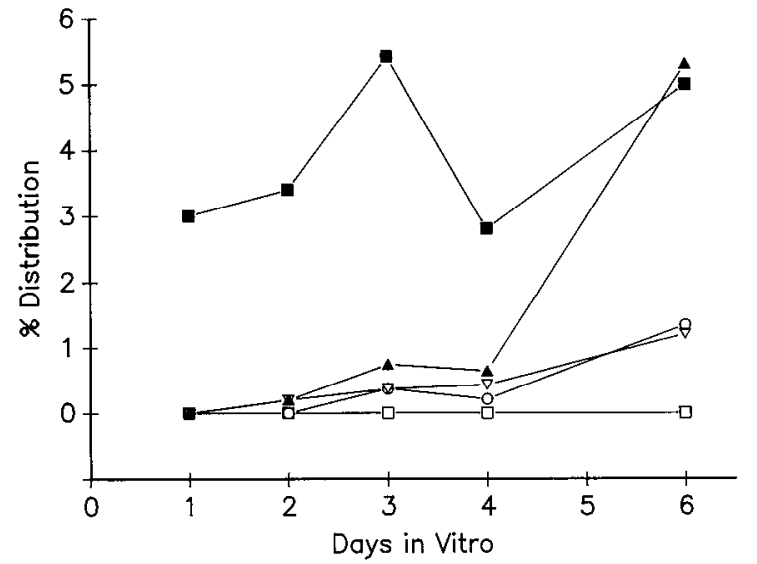

Figure 1. Isolated bovine cells growing in MEM-calf serum. The percentage of the total numbers of cells counted that exhibited a particular cell phenotype are plotted versus days in culture. The results of one typical experiment are shown. Symbols: $\mathbf{m}$, round $\mathrm{GD}_{3}+$ cells; $\boldsymbol{\Lambda}$, total $\mathrm{GC}$ - flat cells; $\mathrm{O}, \mathrm{GD}_{3}+/ \mathrm{GFAP}-$ flat cells; $\nabla, \mathrm{GD}_{3}+/ \mathrm{GFAP}+$ flat cells: $\square, G D_{3}-/ G F A P+$ flat cells (all zero during the $6 \mathrm{~d}$ period of the experiment). The balance of the cells in the culture were $\mathrm{GC}+/ \mathrm{GD}_{3}-$. They constituted the bulk of the cells $(97-89.4 \%)$ and were not plotted.

er than oligodendroglia, that were process-free (see Fig. $3 B$ ). This category constituted $3-5 \%$ of the total during 1-6 DIV. The second category we have termed, for the sake of convenience, flat cells. These GC- cells were first evident at 2-3 DIV as mono- or bipolar cells and at later times assumed a typical astrocytic appearance (see Fig. 3). The flat cells were not phenotypically homogeneous but were composed of $\mathrm{GD}_{3}+/ \mathrm{GFAP}-$ (Fig. 3, $A-C$ ), $\mathrm{GD}_{3}+/ \mathrm{GFAP}+$ (Fig. 3, $D-I$ ), GD $-/ \mathrm{GFAP}-$ (Fig. 3, $D-F$ ), and eventually $\mathrm{GD}_{3}-/$ GFAP + cells (Fig. 3, $J$, $K$ ). All of these flat cells were vimentin + (not shown here, but see Norton et al., 1988).

The cell phenotypes, with the exception of the total flat cells, are presented in Figure 1 as nonoverlapping populations. On day 1 ( $24 \mathrm{hr}$ after plating), there were only oligodendrocytes and $\mathrm{GD}_{3}+$ round cells. After a day or two, the latter cells grew small processes (illustrated for rat cultures in Fig. 6B). The first GFAP+ cells appeared at 2 DIV and steadily increased in number until by 6 DIV they were $1.2 \%$ of the total. All of the GFAP + cells were also $\mathrm{GD}_{3}+$ during this period; no $\mathrm{GD}_{3}-/ \mathrm{GFAP}+$ cells were detected. Note that at both 3 and 4 DIV the flat cells consisted entirely of $\mathrm{GD}_{3}+$ cells, which were divided about equally into $\mathrm{GD}_{3}+/ \mathrm{GFAP}+$ and $\mathrm{GD}_{3}+/ \mathrm{GFAP}-$ phenotypes. At 6 DIV, however, about half of the flat cells were $\mathrm{GD}_{3}-$, and $75 \%$ were GFAP - . Data beyond 6 DIV have not been presented because after this time the flat cells proliferated too rapidly for accurate counting. At $10 \mathrm{DIV}$, however, the majority of flat cells were still GFAP - and also $\mathrm{GD}_{3}-$. By 2 weeks in culture, all of the fiat cells were $\mathrm{GD}_{3}-$. We know that eventually, when grown in 01 medium, all of these flat cells will become GFAP+/vimentin + astrocytes (Norton et al., 1988).

The results of other experiments in MEM-calf serum gave very similar developmental sequences, but the timing of changes in phenotypes could vary by $\pm 1 \mathrm{~d}$, making it impractical to present averages of several experiments on the same graph. The important results, however, were completely reproducible; during the first week, all GFAP + cells were $\mathrm{GD}_{3}+$, and no GFAP + cells were detected at 1 DIV.

A logical sequence can be inferred from these staining pat- 


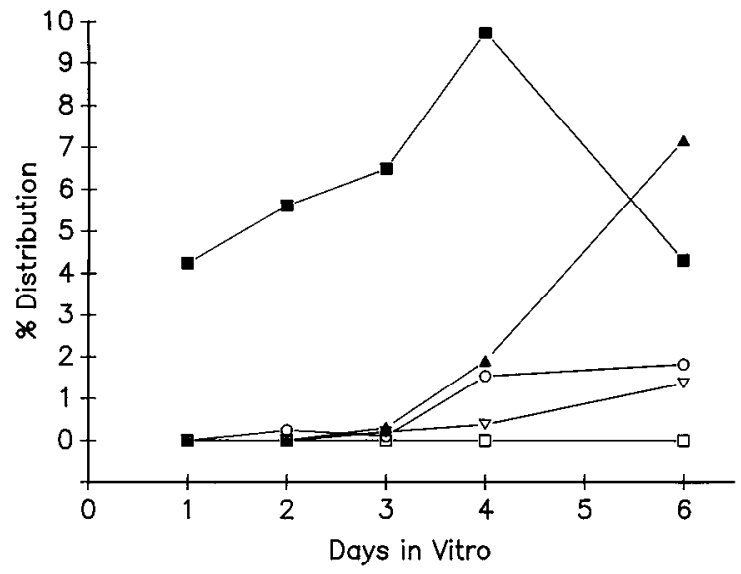

Figure 2. Isolated bovine cells growing in MEM-fetal calf serum. The cell percentages are plotted as in Figure 1 . The results of a typical experiment are shown. Symbols: $\square$, round $\mathrm{GD}_{3}+$ cells; $\boldsymbol{\Lambda}$, total flat cells; $0, \mathrm{GD}_{3}+/ \mathrm{GFAP}-$ flat cells; $\nabla, \mathrm{GD}_{3}+/ \mathrm{GFAP}+$ flat cells; $\square, \mathrm{GD}_{3}-1$ GFAP + flat cells (all zero during the $6 \mathrm{~d}$ of the experiment). As in Figure $1, \mathrm{GC}+/ \mathrm{GD}_{3}-$ cells constitute the balance of the cells in the culture.

terns. The round $\mathrm{GD}_{3}+/ \mathrm{GFAP}-$ cells give rise to small processbearing $\mathrm{GD}_{3}+/$ vimentin $+/ \mathrm{GFAP}-$ cells, which rapidly proliferate. A certain percentage become $\mathrm{GD}_{3}+/$ vimentin $+/ \mathrm{GFAP}+$, and then lose $\mathrm{GD}_{3}$, but the bulk of them in this medium lose $\mathrm{GD}_{3}$ before they express GFAP.

\section{In MEM-fetal calf serum}

The results for a typical experiment in this medium (Fig. 2) for days 1-6 were very similar to those in Figure 1 and support the same sequence of events deduced above, but the kinetics of expression of GFAP was quite different at later times. In this medium, as in MEM-calf serum, all GFAP+ cells were $\mathrm{GD}_{3}+$ up to 6 DIV. At 4 DIV all flat cells were $\mathrm{GD}_{3}+$, but by 6 DIV many had lost $\mathrm{GD}_{3}$ and were also GFAP- (Fig. $3, A-C$ ). By 10 DIV, in contrast to the behavior of these cells in MEM-calf serum, all flat cells were GFAP+/vimentin + and most were $\mathrm{GD}_{3}-$ (Fig. 3, $J, K$ ). Thus, between 6 and $10 \mathrm{DIV}$, the number of $\mathrm{GD}_{3}-/ \mathrm{GFAP}+$ cells rose from zero to account for all of the rapidly increasing number of flat cells, showing that in the fetal calf serum medium the $\mathrm{GD}_{3}-$ /vimentin + cells expressed GFAP much earlier than in calf serum medium.

Rat cells

\section{In MEM-calf serum}

The results for the behavior of rat oligodendrocyte fractions in this medium are given in Figure 4. Numbers for days 1-4 are averages of 3 separate experiments, and days 5, 6, and 11 are single experiments. This graph differs from those for bovine cells in that $\mathrm{GD}_{3}+$ cells are not separated into round and flat categories since the round, process-free $\mathrm{GD}_{3}+$ cells were only prominent at 1 DIV (Fig. $6 B$ ), thereafter assuming an astrocytic morphology.

The major differences between the rat and bovine cultures were that the plating efficiency was lower by a factor of $4-5$, the numbers of oligodendrocytes declined much faster, and the astrocytes began to increase and differentiate much earlier in rat cultures. On the other hand, the proliferation of astrocytes slowed down earlicr in the rat cultures. These somewhat sparser culturcs permitted accurate counts of some phenotypes over a longer period. Beyond 6 DIV, however, it was impossible to obtain accurate counts of GC+ cells, which formed large clumps, or of the total GC- flat cells. As in bovine cultures, all the flat cells were vimentin + .

The percentage of $\mathrm{GD}_{3}+/ \mathrm{GFAP}-$ cells was initially higher in the rat cultures than in the bovine cultures, amounting to 9$10 \%$ of the total cells at $1-2$ DIV (Fig. 4). These cells gradually diminished in amount with time in culture. As these cells gradually diminished, the $\mathrm{GD}_{3}+/ \mathrm{GFAP}+$ cells increased from zero at $1 \mathrm{DIV}$ to $20 \%$ at $5 \mathrm{DIV}$, and then declined to $1-2 \%$ of the total at 11 DIV. The percentage of $\mathrm{GD}_{3}-/ \mathrm{GFAP}+$ cells increased steadily throughout the whole period. The curves for the percentages of $\mathrm{GD}_{3}+/ \mathrm{GFAP}-$ cells, $\mathrm{GD}_{3}+/ \mathrm{GFAP}+$ cells, and $\mathrm{GD}_{3}-/ \mathrm{GFAP}+$ cells followed quite well what would be expected for precursor-product relationships for the following sequence: $\mathrm{GD}_{3}+/ \mathrm{GFAP}-\rightarrow \mathrm{GD}_{3}+/ \mathrm{GFAP}+\rightarrow \mathrm{GD}_{3}-/ \mathrm{GFAP}+$. The kinetics of these changes were, however, quite different from those observed for bovine cultures. In the latter cultures, all the GFAP + cells were also $\mathrm{GD}_{3}+$ through 6 DIV and $\mathrm{GD}_{3}-1$ GFAP+ cells were not observed until much later times.

Note that at 3 and 4 DIV the GC- flat cells were accounted for entirely by cells that were either $\mathrm{GD}_{3}+$ or GFAP+ or both. At 5 DIV, however, all the GC- flat astrocyte-like cells were GFAP + , about half of these being also $\mathrm{GD}_{3}+$. At later times, however, as we found in bovine cultures, there were astrocytictype cells that were neither GFAP + or $\mathrm{GD}_{3}+$. These were presumably cells that had lost $\mathrm{GD}_{3}$ expression but had not yet gained GFAP, although some might have been fibroblastlike cells.

\section{In MEM-fetal calf serum}

The sequence of expression of the antigens $\mathrm{GD}_{3}$ and GFAP was the same in this medium (Fig. 5) as in MEM-calf serum (Fig. 4). The $\mathrm{GD}_{3}+/ \mathrm{GFAP}-$ cells decreased in a regular fashion. This drop coincided with a rise in $\mathrm{GD}_{3}+/ \mathrm{GFAP}+$ cells from zero at 1 DIV to $20 \%$ of the total cells at $4 \mathrm{DIV}$, followed by a slower rise of $\mathrm{GD}_{3}-/ \mathrm{GFAP}+$ cells (see Fig. $6, C-E$ for examples of $\mathrm{GD}_{3}+/ \mathrm{GFAP}+$ and $\mathrm{GD}_{3}-/ \mathrm{GFAP}+$ cells).

In FCS medium there were, at 3 and 4 DIV, always some $\mathrm{GC}-$ /vimentin + astrocytic-like cells that were GFAP- and $\mathrm{GD}_{3}-$ (Fig. 5), whereas in calf serum medium at these times (Fig. 4), all of the astrocytic-like GC- cells were GFAP + . Thus, during the first few days in FCS the sequence $\mathrm{GD}_{3}+/$ vimentin $+/$ GFAP $-\rightarrow \mathrm{GD}_{3}-/$ vimentin $+/ \mathrm{GFAP}-$ competed more strongly with the sequence $\mathrm{GD}_{3}+/$ vimentin $+/ \mathrm{GFAP}-\rightarrow \mathrm{GD}_{3}+/$ vimentin $+/$ GFAP $+\rightarrow \mathrm{GD}_{3}-/$ vimentin $+/$ GFAP + than in CSmedium. Since eventually the vimentin + cells became GFAP + , we presume the former sequence goes as follows: $\mathrm{GD}_{3}+/ \mathrm{vi}-$ mentin $+/$ GFAP $\rightarrow \mathrm{GD}_{3}-/$ vimentin $+/$ GFAP $-\rightarrow \mathrm{GD}_{3}-/$ vimentin $+/$ GFAP + . Another difference between rat cultures in $\mathrm{CS}$ and FCS is that the rate of conversion of $\mathrm{GD}_{3}+/ \mathrm{GFAP}+$ cells to $\mathrm{GD}_{3}-/ \mathrm{GFAP}+$ cells was slower in FCS medium.

\section{Discussion}

The results reported here show that $\mathrm{GD}_{3}+$ glial precursor cells are present in the brains of 2 species studied at quite different developmental stages. These cells, which are isolated together with oligodendrocytes and comprise $10 \%$ or less of the initial oligodendroglial fractions, give rise in culture to astrocytes. We have obtained no evidence to indicate that under our culture conditions they might also differentiate into oligodendrocytes. It is not possible to conclude that all astrocytes that develop in 
772 Norton and Farooq - Astrocyte Precursors in Mature Brain
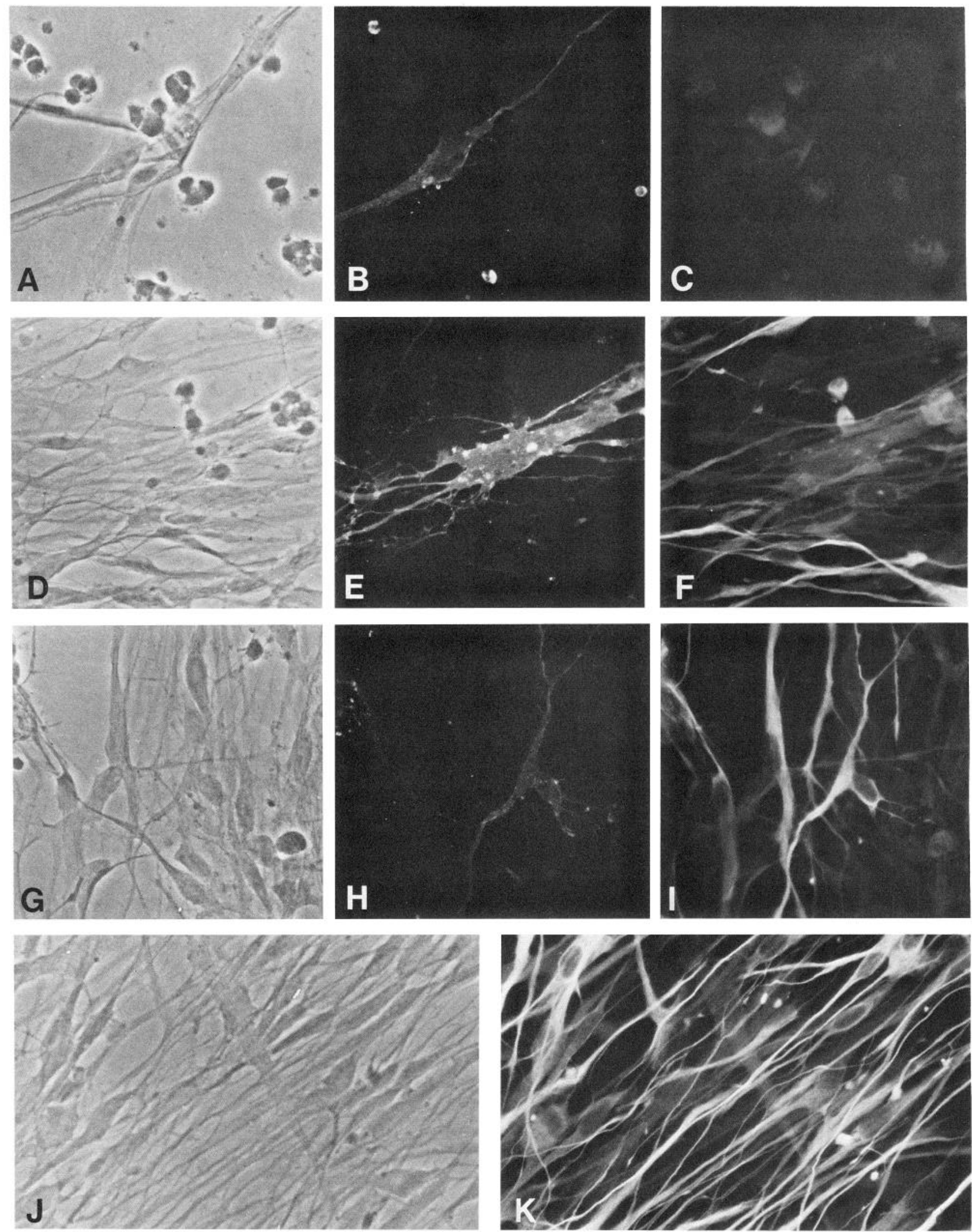

Figure 3. Examples of bovine cultures grown in MEM-fetal calf serum, double-immunostained for $\operatorname{GD}_{3}(B, E, H)$ and $G F A P(C, F, I, K)$. Cultures grown in MEM-calf serum had a nearly identical appearance. $A-C$, Seven DIV. This field shows portions of 6 astrocyte-like cells plus several small clumps of oligodendroglia. One of the astrocyte-like cells is $\mathrm{GD}_{3}+/ \mathrm{GFAP}-$. The remainder are negative for both antigens. Note the 3 small round $\mathrm{GD}_{3}+$ cells. The oligodendrocytes are negative for both antigens. $D-F$, Nine DIV. This field has one large cell that is strongly positive for GD but only weakly GFAP+. There are also several GFAP+ astrocyte processes that are $\mathrm{GD}_{3}-$. Other flat cells are negative for both antigens. $G-I$. The same culture as in $D-F$. A number of GFAP+ astrocytes, only one of which is weakly $\mathrm{GD}_{3}+. J$ and $K$, Ten DIV. The number of GFAP+ cells has increased greatly. At this time in culture all astrocytes are $\mathrm{GD}_{3}-$ (the completely black $\mathrm{GD}_{3}$-immunostained field has been omitted). 


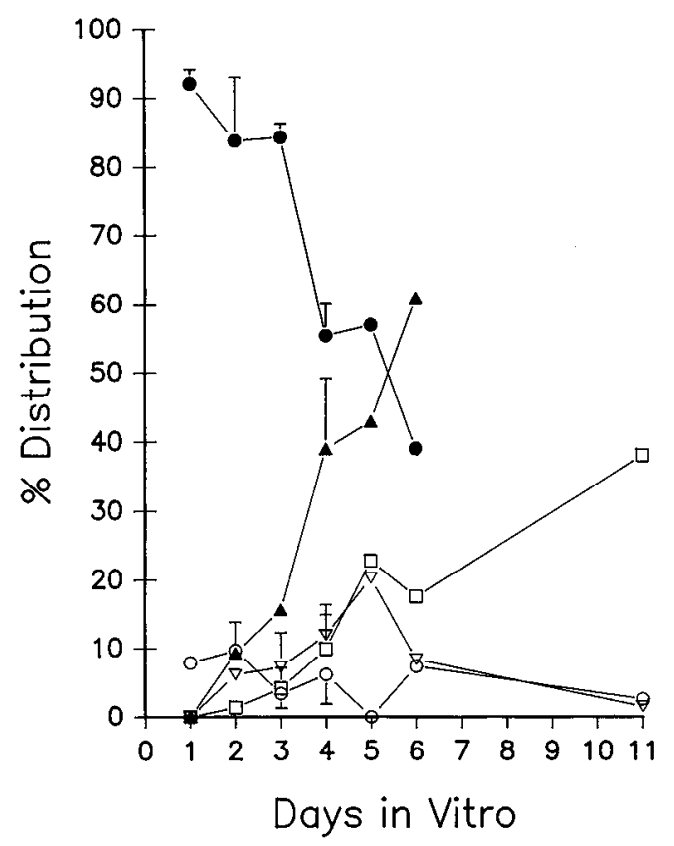

Figure 4. Cells isolated from 30-d-old rat forebrain growing in MEMcalf serum. The amount of each cell phenotype, expressed as a percentage of total cells counted is plotted versus days in culture. This graph differs from Figures 2 and 3 in that GC+ cells are also plotted. The results for days $1-4$ are averages \pm SD of 3 separate experiments; days 5,6 , and 11 are single experiments. Symbols: $\bullet, G C+$ oligodendrocytes; $\boldsymbol{\Lambda}$, total $\mathrm{GC}$ - flat cells; $\mathrm{O}, \mathrm{GD}_{3}+/ \mathrm{GFAP}-$ flat cells; $\nabla, \mathrm{GD}_{3}+/ \mathrm{GFAP}+$ flat cells; $\square, \mathrm{GD}_{3}-/ \mathrm{GFAP}+$ flat cells.

these cultures derive from the $\mathrm{GD}_{3}+$ cells, although it is highly probable that they do. During the first week in bovine cultures all GFAP+ astrocytes were also $\mathrm{GD}_{3}+$, but in the rat cultures there were always a few $\mathrm{GD}_{3}-/ \mathrm{GFAP}+$ cells even at the early stages in culture when astrocytes were first detected.

At any one time there is a mixture of phenotypes in the cultures, but the kinetics of their appearance and disappearance permits the construction of the following sequences to describe the conversion of the precursor cells to astrocytes.

$$
\text { Round } \mathrm{GD}_{3}+/ \mathrm{GFAP}-\text { cells }
$$

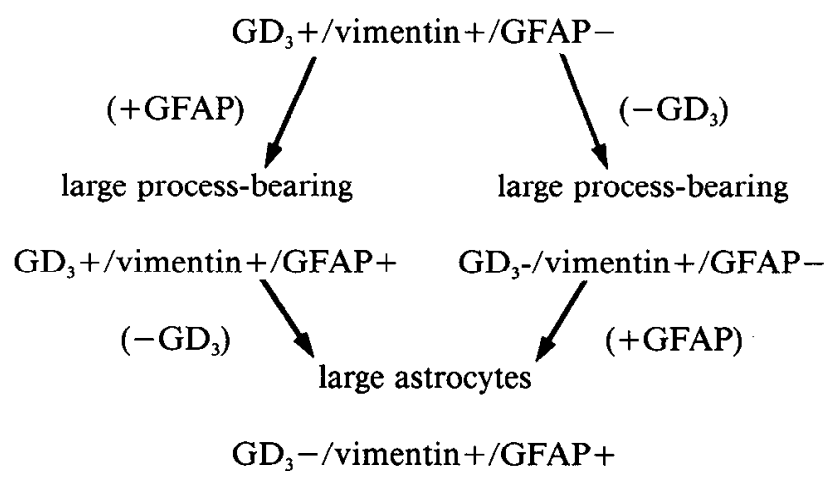

The speed of this process and the percentage of cells that differentiate by each of the 2 parallel sequences is dependent on

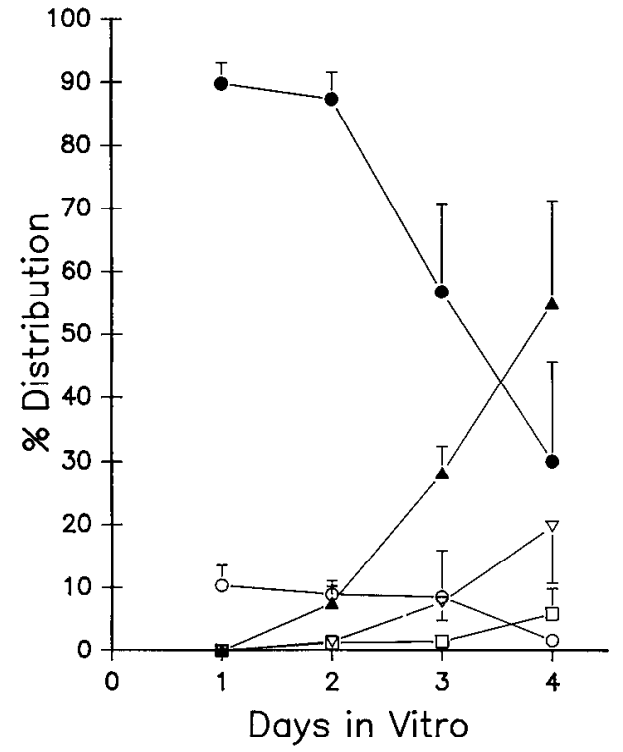

Figure 5. Cells isolated from 30-d-old rat forebrain growing in MEMfetal calf serum. Results are plotted as in Figure 4. Results are the averages $\pm \mathrm{SD}$ for 4 separate experiments. Symbols: $\bullet, \mathrm{GC}+$ oligodendrocytes; $\boldsymbol{\Delta}$, total $\mathrm{GC}-$ flat cells; $O, \mathrm{GD}_{3}+/ \mathrm{GFAP}-$ flat cells; $\nabla$, $\mathrm{GD}_{3}+/ \mathrm{GFAP}+$ flat cells; and $\square, \mathrm{GD}_{3}-/ \mathrm{GFAP}+$ flat cells.

the species and the culture medium, as we have described under Results. Many other unknown factors are undoubtedly also involved, including the developmental stage of the animals.

The sequence proposed here for the conversion of glial precursor cells to astrocytes is the same as that deduced by Goldman et al. (1986) for the generation of astrocytes in neonatal rat cultures. There is a major difference, however, between our more mature cultures and the neonatal cultures. The latter contain a population of bipotential $\mathrm{GD}_{3}+($ and $\mathrm{A} 2 \mathrm{~B} 5+$ ) cells that remain in the culture after most of the astrocytes have formed and become confluent. This population of small cells gives rise to oligodendrocytes in serum-free or low-serum media and to astrocytes in media containing high serum (Raff et al., 1983; Saneto and deVellis, 1985; Goldman et al., 1986). We have never seen in our cultures cells that we considered positive for both $\mathrm{GD}_{3}$ and $\mathrm{GC}$, and, as we have shown previously (Norton et al., 1986, 1988), astrocytes proliferate well when the medium in our cultures is changed to a serum-free medium at a time when thc $\mathrm{GD}_{3}+$ cells are beginning to differentiate. Our results differ considerably from those of Kim et al. (1986), who found that all oligodendrocytes cultured from adult human brain were $\mathrm{GD}_{3}+$. Goldman et al. (1986) also found that $\mathrm{GC}+$ cells in neonatal rat cultures were derived from $\mathrm{GD}_{3}+$ cells and retained $\mathrm{GD}_{3}$ at least up to $30 \mathrm{DIV}$. On the other hand, mature oligodendrocytes in situ do not bind the $\mathrm{GD}_{3}$ antibody (Goldman et al., 1984; LeVine and Goldman, 1988), even though $\mathrm{GD}_{3}$ is a major ganglioside of isolated oligodendrocytes from either rat or bovine brain ( $\mathrm{Yu}$ et al., 1986).

The validity and utility of $\mathrm{GD}_{3}$ as a marker for immature neuroectodermal cells has been amply demonstrated (Goldman et al., 1984, 1986; LeVine and Goldman, 1988). This marker has also been shown to be present on cells of the subventricular germinal zone of adult rats (J. E. Goldman, personal communication). The present study is the first to show that $\mathrm{GD}_{3}+$ cells are also present in the mature bovine brain and that these $\mathrm{GD}_{3}$ cells in mature brain can act as glial precursors in vitro. 

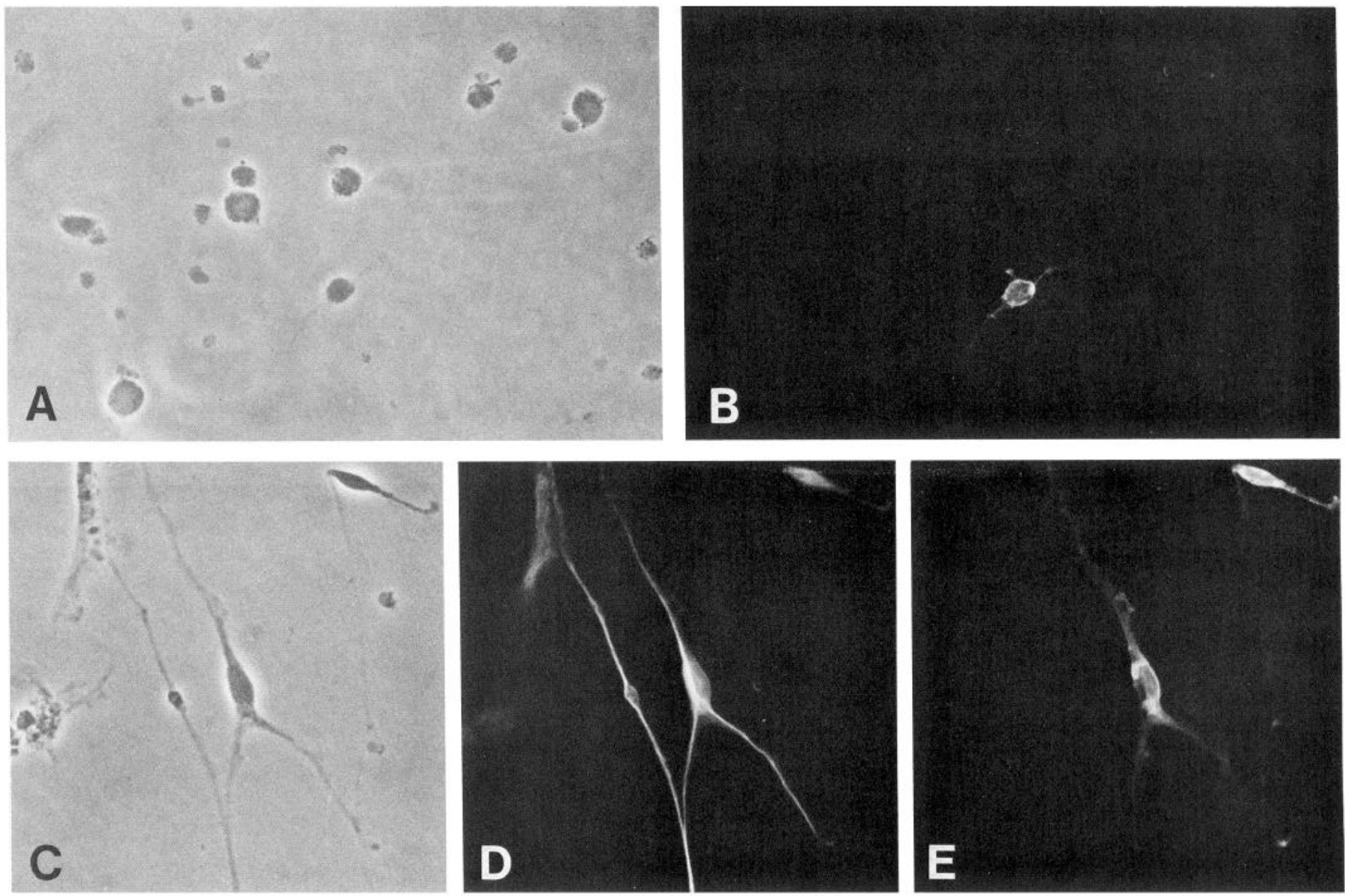

Figure 6. Examples of rat cultures grown in MEM-fetal calf serum, double-immunostained for $\mathrm{GD}_{3}(B, E)$ and GFAP $(D)$. $A$ and $B$, One DIV. One $\mathrm{GD}_{3}+$ cell is present that has grown 3 small processes. The remaining intact cells are $\mathrm{GD}_{3}-$ oligodendroglia. None of the cells in this culture was GFAP+ (photograph omitted). $C-E$, Four DIV. Portions of 3 GFAP+ astrocytes are shown $(D), 2$ of which are GD $+(E)$.

It is not surprising that cell isolates of mature brain should contain significant numbers of glioblasts. It was shown about 25 years ago that cells in the adult rodent brain can incorporate ${ }^{3}$ H-thymidine (Smart, 1961; Smart and Leblond, 1961). Significant nuclear labeling is found even in animals of $400 \mathrm{~d}$ of age (Dalton et al., 1968). The bulk of the labeled cells are found in the subventricular germinal zone at the borders of the lateral ventricles radiating out under the corpus callosum (Smart, 1961; Altman, 1966; Lewis, 1968; Ludwin, 1985), but labeled cells are also found scattered throughout the brain (Smart and Leblond, 1961; Hommes and Leblond, 1967; Dalton et al., 1968; Korr et al., 1973). With increasing age, the subventricular zone decreases in size and the number of labeled cells diminishes, but it is still present even in adulthood. The mitotic cells in this zone are, at all ages, undifferentiated blast cells. The scattered cells that take up thymidine are apparently glia but have been considered to be mostly oligodendrocytes rather than astrocytes (Hommes and Leblond, 1967). ffrench-Constant and Raff (1986) have reported that proliferating bipotential progenitor cells can be cultured from adult rat optic nerve (although less than 200 of these cells were obtained per nerve after $2 \mathrm{~d}$ in vitro). Brammer (1986) has also shown that oligodendrocytes isolated from 30-d-old rat brain by the technique developed in this laboratory (Snyder et al., 1980) contain 20-25\% A2B5+/ $\mathrm{GC}-$ cells, presumably glial precursors. One must therefore assume that adult bovine brain also contains glioblasts capable of cell division.

The behavior of cells in culture represents, at minimum, part of their entire potential repertoire, but may not accurately reflect the true function of the cells in vivo. For example, $\mathrm{GD}_{3}+$ cells in neonatal cultures generate both astrocytes and oligodendrocytes, but at this age in vivo there is evidence that they act only as oligodendrocyte precursors (LeVine and Goldman, 1988). Can we then deduce the possible function of glial precursor cells in the adult brain from the results reported here? It has long been known that there is some proliferation of astrocytes in response to trauma (although there is perhaps more hypertrophy than hyperplasia in the usual gliotic response), and it is now quite well established that oligodendrocytes also proliferate following an excision lesion (Ludwin, 1985; Ludwin and Bakker, 1988) or in developing multiple sclerosis plaques (Raine et al., 1981b). The source of these glia is not known, but it is not improbable that they might arise from the pool of precursor cells rather than from fully differentiated glia.

Our results have no implications for the generation of oligodendrocytes in the mature CNS, but they do for astrocytes. Ganglioside $\mathrm{GD}_{3}$ is a prominent ganglioside of the immature CNS but decreases significantly with development and maturation (reviewed by Seyfried and $\mathrm{Yu}, 1985$ ). Because of this developmental pattern, it had long been assumed that $\mathrm{GD}_{3}$ was 
a characteristic component of immature, undifferentiated CNS cells. There are still small but measurable amounts of this ganglioside in the normal adult brain. Reactive astrocytes in gliosed tissue are, however, exceptions. Areas of gliosed brain are characterized by very high levels of $\mathrm{GD}_{3}$ (see Seyfried and $\mathrm{Yu}, 1985$, and LeVine et al., 1986 for reviews), and the reactive astrocytes in cerebellar mutants in which neuronal degeneration occurs react strongly with an antibody to $\mathrm{GD}_{3}$, whereas normal astrocytes do not (LeVine et al., 1986). Another characteristic of reactive astrocytes induced by trauma is that those adjacent to the wound express vimentin, whereas most normal astrocytes (and most reactive astrocytes) do not (Dahl et al., 1981; Pixley and deVellis, 1984; Schiffer et al., 1986; Takamiya et al., 1988). Thus, a population of reactive astrocytes in adult brain contain 2 antigens, $\mathrm{GD}_{3}$ and vimcntin, that are not present in the vast majority of normal astrocytes but that are present in astrocytes that develop in vitro from glial precursors obtained from the mature CNS. It is possible that the glial precursor cells in the adult brain serve as one source of reactive astrocytes.

\section{References}

Altman, J. (1966) Proliferation and migration of undifferentiated precursor cells in the rat during postnatal gliogenesis. Exp. Neurol. 16: 263-278.

Bottenstein, J. E. (1986) Growth requirements in vitro of oligodendrocyte cell lines and neonatal rat brain oligodendrocytes. Proc. Natl. Acad. Sci. USA 83: 1955-1959.

Bovolenta, P., R. K. H. Liem, and C. A. Mason (1984) Development of cerebellar astroglia: Transitions in form and cytoskeletal content. Dev. Biol. 102: 248-259.

Brammer, M. J. (1986) Lipid synthesis in oligodendroglia and putative glioblasts isolated from developing rat brain. Adv. Biosci. 61: 287294.

Chiu, F.-C., and J. E. Goldman (1984) Synthesis and turnover of cytoskeletal proteins in cultured astrocytes. J. Neurochem. 42: 166174.

Chiu, F.-C., W. T. Norton, and K. L. Fields (1981) The cytoskeleton of primary astrocytes in culture contains actin, glial fibrillary acidic protein, and the fibroblast-type filament protein, vimentin. J. Neurochem. 37: 147-155.

Dahl, D., A. Bignami, K. Weber, and M. Osborn (1981) Filament proteins in rat optic nerves undergoing Wallerian degeneration: Localization of vimentin, the fibroblastic 100-A filament protein in normal and reactive astrocytcs. Exp. Ncurol. 73: 496-506.

Dalton, M. M., O. R. Hommes, and C. P. Leblond (1968) Correlation of glial proliferation with age in the mouse brain. J. Comp. Neurol. 134: 397-399.

Farooq, M., W. Cammer, D. S. Snyder, C. S. Raine, and W. T. Norton (1981) Properties of bovine oligodendroglia isolated by a new procedure using physiologic conditions. J. Neurochem. 36: 431-440.

ffrench-Constant, C., and M. C. Raff (1986) Proliferating bipotential glial progenitor cells in adult rat optic nerve. Nature 319:499-502.

Goldman, J. E., and F.-C. Chiu (1984) Growth kinetics, cell shape, and the cytoskeleton of primary astrocyte cultures. J. Neurochem. 42. $175-184$.

Goldman, J. E., M. Hirano, R. K. Yu, and T. N. Seyfried (1984) $G_{D 3}$ ganglioside is a glycolipid characteristic of immature neuroectodermal cells. J. Neuroimmunol. 7: 179-192.

Goldman, J. E., S. S. Geier, and M. Hirano (1986) Differentiation of astrocytes and oligodendrocytes from germinal matrix cells in primary culture. J. Neurosci. 6: 52-60.

Hommes, O. R., and C. P. Leblond (1967) Mitotic division of neuroglia in the normal adult rat. J. Comp. Neurol. 129: 269-278.

Juurlink, B. H. J., S. Fedoroff; C. Hall, and E. J. H. Nathaniel (1981)
Astrocyte cell lineage. I. Astrocyte progenitor cells in mouse neopallium. J. Comp. Neurol. 200: 375-391.

Kim, S. U., G. Moretto, V. Lee, and R. K. Yu (1986) Neuroimmunology of gangliosides in human neurons and glial cells in culture. $J$. Neurosci. Res. 15: 303-321.

Korr, H., B. Schultze, and W. Maurer (1973) Autoradiographic investigations of glial proliferation in the brain of adult mice. J. Comp. Neurol. 150: 169-176.

LeVine, S. M., and J. E. Goldman (1988) Embryonic divergence of oligodendrocyte and astrocyte lineages in developing rat cerebrum. J. Neurosci. 8: 3992-4006.

LeVine, S. M., T. N. Seyfried, R. K. Yu, and J. E. Goldman (1986) Immunocytochemical localization of $\mathrm{G}_{\mathrm{D}_{3}}$ ganglioside to astrocytes in murine cerebellar mutants. Brain Res. 374: 260-269.

Lewis, P. D. (1968) A quantitative study of cell proliferation in the subependymal layer of the adult rat brain. Exp. Neurol. 20: 203-207.

Ludwin, S. K. (1985) Reaction of oligodendrocytes and astrocytes to trauma and implantation. Lab. Invest. 52: 20-30.

Ludwin, S. K., and D. A. Bakker (1988) Can oligodendrocytes attached to myelin proliferate? J. Neurosci. 8: 1239-1244.

Norton, W. T., M. Farooq, F.-C. Chiu, and J. E. Bottenstein (1986) Properties of cultures derived from mature, isolated oligodendroglia. Adv. Biosci. 61: 41-47.

Norton, W. T., M. Farooq, F.-C. Chiu, and J. E. Bottenstein (1988) Pure astrocyte cultures derived from cells isolated from mature brain. Glia (in press).

Pixley, S. R., and J. deVellis (1984) Transition between immature radial glia and mature astrocytes studied with a monoclonal antibody to vimentin. Dev. Brain Res. 15: 201-209.

Pukel, C. S., K. O. Lloyd, L. R. Travassos, W. G. Dippold, H. F. Oettgen, and L. J. Old (1982) $\mathrm{G}_{\mathrm{D} 3}$, a prominent ganglioside of human melanoma. J. Exp. Med. 155: 1133-1147.

Raff, M. C., R. H. Miller, and M. Noble (1983) A glial progenitor cell that develops in vitro into an astrocyte or an oligodendrocyte depending on culture medium. Nature 303: 390-396.

Raine, C. S., A. B. Johnson, D. M. Marcus, A. Suzuki, and M. B. Bornstein (1981a) Demyelination in vitro. Absorption studies demonstrate that galactocerebroside is a major target. J. Neurol. Sci. 52: $117-131$.

Raine, C. S., L. Scheinberg, and J. M. Waltz (1981b) Multiple sclerosis-Oligodendrocyte survival and proliferation in an active established lesion. Lab. Invest. 45: 534-546.

Saneto, R. P., and J. deVellis (1985) Characterization of cultured rat oligodendrocytes proliferating in a serum-free, chemically defined medium. Proc. Natl. Acad. Sci. USA 82: 3509-3513.

Schiffer, D., M. T. Giordana, A. Migheli, G. Giaccone, S. Pezzotta, and A. Mauro (1986) Glial fibrillary acidic protein and vimentin in the experimental glial reaction of the rat brain. Brain Res. 374: 110-118.

Scyfricd, T. N., and R. K. Yu (1985) Ganglioside $G_{\mathrm{D}_{3}}$ : Structurc, cellular distribution, and possible function. Mol. Cell. Biochem. 68: $3-10$.

Smart, I. (1961) The subependymal layer of the mouse brain and its cell production as shown by radioautography after thymidine- $\mathrm{H}^{3}$ injection. J. Comp. Neurol. 116: 325-347.

Smart, I., and C. P. Leblond (1961) Evidence for division and transformations of neuroglia cells in the mouse brain, as derived from radioautography after injection of thymidine- $\mathrm{H}^{3}$. J. Comp. Neurol. 116: 349-367.

Snyder, D. S., C. S. Raine, M. Farooq, and W. T. Norton (1980) The bulk isolation of oligodendroglia from whole rat forebrain: A new procedure using physiologic media. J. Neurochem. 34: 1614-1621.

Takamiya, Y., S. Kohsaka, S. Toya, M. Otani, and Y. Tsukada (1988) Immunohistochemical studies on the proliferation of reactive astrocytes and the expression of cytoskeletal proteins following brain injury in rats. Dev. Brain Res. 38: 201-210.

Yu, R. K., L. J. Macala, M. Farooq, R. L. Ledeen, and W. T. Norton (1986) Ganglioside composition of rat and bovine oligodendroglia. Trans. Am. Soc. Neurochem. 17: 270. 